\title{
Una introducción al análisis del racismo: el contexto español como caso de estudio ${ }^{1}$
}

Mi objetivo principal a la hora de abordar un fenómeno tan complejo como el del racismo, no es hacer un análisis exhaustivo del problema, sino ofrecer algunas ideas útiles desde una perspectiva antropológica para tratar de entenderlo en un marco sociocultural. Mi intención es emplear como materiales los discursos, las actitudes y los comportamientos racistas que se producen en una interacción social, y darles un sentido en dicha interacción.

He elegido el contexto español como caso de estudio, y tengo intención de utilizarlo como un ejemplo fecundo para proponer hipótesis, contrastar variables, desechar las que resulten inservibles y proponer las que funcionen, como contribución al desarrollo de un modelo teórico para el análisis del racismo.

\section{EL RACISMO VISIBLE EN ESPAÑA}

Me gustaría comenzar tratando el racismo que ha sido precibido en España y algunas de las conclusiones que se han extraído de esas percepciones; es decir, dónde se ha observado el fenómeno y cuáles han sido las principales variables que se han empleado para explicarlo. La producción dedicada al tema del racismo en España pertenece a distintos campos, la mayoría de ellos relacionados con las ciencias sociales, pero no exclusivamente. Además existen informes de organismos oficiales y no oficiales dedicados al tema, y varias encuestas (oficiales y no oficiales también) que han llegado ampliamente a la opinión pública difundidas por los medios de comunicación.

1 Una versión anterior de este texto formó parte del XVII Curso de Etnología Española "Julio Caro Barojan: Historia y actualidad de la antropología en España, que se celebró en el Departamento de Antropología de España y América del CSIC durante el mes de abril de 1997. Agradezco a Mercedes García-Arenal, Fernando Monge y Carmen Ortiz los comentarios que hicieron a formulaciones anteriores: creo que todos ellos han contribuido a conseguir una argumentación más clara y a la vez más compleja. 
De un análisis de todos estos materiales se desprende una primera idea muy significativa: la preocupación por el tema del racismo en España es muy reciente, y por lo tanto escasa. Y resulta más llamativa aún si hacemos una comparación con lo que ocurre en otros países, por ejemplo en los Estados Unidos donde, aunque es un tema que en la actualidad no ha perdido en absoluto ni vigencia ni interés, cuenta con una amplia y larga tradición de estudio, sobre la que me gustaría llamar la atención porque existen excelentes trabajos aplicables fácilmente al caso español.

Una segunda característica de la producción en España sobre racismo, sería su tratamiento asociado al tema de la inmigración. No en todos los casos, pero sí en la mayoría, se contempla exclusivamente en relación con la presencia de inmigrantes, y casi siempre como un fenómeno derivado de ella.

Dentro de este panorama he elegido un ejemplo que voy a citar ampliamente. Se trata de un caso representativo, publicado en 1996, en un trabajo más amplio, y es quizá uno de los más recientes estudios dedicados al tema. Me refiero al artículo de Carlos Celaya titulado "El mapa de la xenofobia en España: una irregular geografía de rechazo" ${ }^{2}$.

El autor utiliza como base los informes recogidos por las ONGs y la prensa sobre 45 casos, a ellos añade la encuesta de opinión sobre los extranjeros por Comunidades Autónomas realizada por el CIS en 1991. Con estos datos trata de analizar el panorama que presenta en España el racismo, no sólo con referencia a los inmigrantes magrebíes, sino en términos generales. Elabora una tipología que distribuye las observaciones recogidas sobre comportamientos racistas en cuatro categorías: A) "asesinatos", B) «apaleamientos más o menos espontáneos (incluidas palizas y malos tratos infringidos por la policía o algún cuerpo de seguridad)", C) "expulsiones masivas como manifestaciones de una política restrictiva" y D) "discriminaciones en espacios públicos o privados (rechazos en bares y pubs, problemas en el arriendo de pisos, problemas en plazas y espacios abiertos en los que confluyen oriundos y extranjeros" ${ }^{3}$. A continuación traslada todas estas categorías a los lugares donde han ocurrido (por comunidades autónomas), y confecciona un mapa cuya información es la que da nombre al artículo. Por último, extrae una serie de conclusiones, que son muy ilustrativas porque le fuerzan a un auténtico callejón sin salida:

$1 .^{\text {a) }}$ "Las opiniones negativas ante los inmigrantes no llevan aparejado el paso a la acción", y explica: "Allí donde se registran las peores opi-

2 Este artículo forma parte de B. LÓPEZ GARCíA, ed., Atlas de la inmigración magrebi en España (Madrid: Universidad Autónoma, 1996), pp. 224-225.

3 Ibid., p. 224. 
niones no se registran [sic] el mayor número de actos racistas". Por otra parte la "percepción" de la inmigración no equivale a "convivencia con" la inmigración. Dicho de otra forma, el peso de los prejuicios en la conciencia colectiva es mayor que el de la realidad del contacto.

2.) "La relación presencia inmigrante/opiniones xenófobas no es automática, [y aclara] en Murcia hay una negativa opinión con respecto a los magrebíes y es la tercera provincia en número de inmigrantes. En Cantabria hay, según la encuesta de 1991 del CIS, la peor de las opiniones hacia los norteafricanos, y es una de las provincias con menos presencia extranjera".

3.a) "Allí donde la presencia de extranjeros es más importante (Madrid y Barcelona) es también donde se han producido los principales atentados", y sin embargo reconoce a continuación: "Pero también se han producido atentados y discriminaciones en lugares en los que la presencia extranjera es mínima (Palencia), escasa (Huelva) o no tan intensa (Baleares) ${ }^{4}$.

En resumen: en la primera conclusión se ve incapaz de establecer una relación entre opiniones racistas y actos racistas, o entre percepción de la inmigración y presencia de la inmigración. En la segunda no puede conectar las variables xenofobia y número de inmigrantes. Y por último, en la tercera, abandona el intento de explicar el número de inmigrantes en función de la presencia de actos racistas o discriminación.

$\mathrm{El}$ análisis se demuestra por lo tanto ineficaz, tanto a la hora de establecer una tipología de la xenofobia en España, como a la de descubrir variables socioculturales para analizar el racismo. No trato de invalidar la investigación realizada por Celaya, pues en mi opinión una conclusión negativa sigue siendo útil, con tal de que quede clara la necesidad de abandonar ese camino. Espero, sin embargo, que este ejemplo resulte suficientemente ilustrativo de la complejidad del fenómeno que estamos abordando. Ahora bien, si las variables que se han elegido en este estudio, representativo del tipo de análisis que se hace en España, no parecen útiles ¿por qué no se abandonan y se buscan otras? ¿por qué tanto las encuestas como otros trabajos sobre racismo siguen tratando el tema en función del número de inmigrantes y del peso simbólico de la inmigración en la sociedad receptora? y ¿por qué continuamos observando las actitudes, opiniones y acciones racistas en relación con los inmigrantes?

Como trataré de demostrar más adelante, las variables seleccionadas han sido condicionadas por los contextos en los que se ha observado el racismo. Veamos otro ejemplo. En una encuesta realizada en mayo de 1991 so-

4 Ibid., p. 224. 
bre 17.687 entrevistas de ámbito nacional ${ }^{5}$, los encuestadores dedican las primeras 31 preguntas a recoger las opiniones de los entrevistados en relación con los trabajadores inmigrantes, y a partir de ese momento empiezan a sondear las actitudes y opiniones racistas de los españoles hacia una serie de grupos que ellos mismos delimitan. Estos grupos son, por orden: "árabes, negros de África, judíos, gitanos, hispanoamericanos, filipinos, portugueses y negros norteamericanos". Más adelante se emplean otras categorías diferentes para recoger opiniones acerca de matrimonios mixtos: "blancos/ negros, blancos/asiáticos, gitanos/no gitanos, españoles/árabes, españoles/ sudamericanos, y españoles/extranjeros en general. Y por último se emplea otro tipo de clasificación: "países de la CEE, Portugal, resto de países occidentales (EE.UU. etc.), países del este, América latina, norte de África (Marruecos, Tunez, Libia, etc.), resto de África (África negra), Asia y Filipinas".

Si he citado pormenorizadamente las categorías empleadas en este sondeo es porque es la base sobre la que se recogen las opiniones, primero, y a continuación se efectúan los análisis, de manera que condicionan de forma muy determinante el tipo de material con el que se elaboran los estudios sobre racismo en España, y establecen a priori una conexión entre inmigración y racismo.

La encuesta incluye además siete últimas preguntas dirigidas exclusivamente a extranjeros (sin especificar su procedencia) y destinadas a sondear sus opiniones y actitudes con respecto a los nacionales; de esta forma el estudio reconoce que son producto de una interacción entre dos tipos de actores sociales, y que es necesario, o al menos conveniente, analizar el fenómeno desde las dos perspectivas. Este presupuesto también tiene eco en estudios posteriores a partir de encuestas o con independencia de ellas, y me gustaría citar como un ejemplo el libro Hablar $y$ dejar bablar. Sobre racismo y xenofobia ${ }^{6}$, donde ya desde el mismo título se trata de señalar la importancia de recoger las opiniones de los extranjeros sobre los nacionales, y se incluyen algunas de modo testimonial ${ }^{7}$.

No obstante, esta doble perspectiva a la hora de observar y analizar el racismo en España continúa siendo prisionera del contexto de la inmi-

5 Bajo el título paradigmático "Inmigración y racismo".

6 MARTín Rojo y otros, eds., (Madrid: Universidad Autónoma, 1994). El panorama de la producción en España sobre inmigración se encuentra compilado hasta 1992 en COLECTIVO IOE, Libros y documentos sobre migraciones (Madrid: Colectivo Ioe, 1992). Otros ejemplos representativos más recientes podrían ser: I. ÁlvAREZ DORRONSORO, Diversidad cultural y conflicto nacional (Madrid: Talasa, 1993). J. CONTRERAS, ed., Los retos de la inmigración. Racismo y pluriculturalidad (Madrid: Talasa, 1994).

7 He comentado ampliamente este libro en una reseña en Arbor, 615, 156 (1997), pp. 126-127. 
gración, porque aunque trate de considerarse desde los dos lados, se hace sólo desde la perspectiva de los actores que intervienen en el proceso inmigratorio: como si fuera una relación que sólo es posible observar desde que España se convirtió, a partir de finales de la década de los 70 y fundamentalmente a lo largo de los 80 , en un país de inmigración.

\section{EL RACISMO INVISIBLE EN ESPAÑA ${ }^{8}$}

Parece como si no existiera racismo más que en el contexto de la inmigración, o, al menos, como si no hubiera llamado la atención de otra forma; quizá por eso no se ha buscado en otro lugar y siga resultando tan necesario determinar qué tipo de relación existe entre el número de inmigrantes afincados en nuestro país y las manifestaciones racistas descubiertas; quizá por eso no se abandonan las variables, aunque no funcionen. Pero no funcionan. Siguen sin ser útiles porque los fenómenos sociales son con frecuencia más complejos de lo que parecen, y también muy a menudo resultan casi invisibles por sutiles. Me propongo a continuación tratar de analizar el racismo que no se ve, el que no se ha percibido a simple vista. Creo que de esta manera podré ofrecer un panorama mucho más completo y complejo, que puede descubrir un sentido distinto, siempre que estemos dispuestos a levantar la capa que esconde el racismo invisible.

Muchos años antes de que España se convirtiera en un país de inmigración reciente, se escribió:

Parece que los gitanos y gitanas solamente nacieron en el mundo para ser ladrones: nacen de padres ladrones, críanse con ladrones, estudian para ladrones, y

8 He utilizado la expresión "racismo invisible" para referirme a un racismo más sutil y menos evidente que el analizado en el apartado anterior; a un racismo que, al menos en su propio contexto, pasa desapercibido como tal, y voy a tratar de demostrarlo a continuación. Otros autores han empleado otras expresiones, por ejemplo T. A. van Dijk lo denomina "Everyday Racism" y lo caracteriza de esta forma: "..., racism does not consist of only white supremacist ideologies of race, or only of aggressive overt or blatant discriminatory acts, the forms of racism as it is currently understood in informal conversations, in the media, or in much of the social sciences. Racism also involves the everyday, mundane, negative opinions, attitudes, and ideologies and the seemingly subtle acts and conditions of discrimination against minorities, namely, those social cognitions and social acts, processes, structures, or institutions that directly or indirectly contribute to the dominance of the white group and the subordinate position of minorities" T. A. VAN DIJK, Elite Discourse and Racism (London: Sage, 1993). En otros lugares yo también he utilizado la expresión "racismo cotidiano", pero creo que para el caso español resulta más adecuado y más gráfico hablar de aracismo invisible". 
finalmente salen con ser ladrones corrientes y molientes a todo ruedo; y la fama del hurtar y el hurtar son en ellos como accidentes inseparables que no se quitan sino con la muerte ${ }^{9}$

Estas palabras fueron escritas en 1612 y con ellas comienza Cervantes nada más y nada menos que Las novelas ejemplares ${ }^{10}$, aquellas que pretendieron ser un ejemplo moral para sus lectores, y que hoy día siguen siendo leídas, si no de esa forma, como una de las creaciones cumbres de la lengua castellana. No es mi intención juzgar con raseros del siglo xx a Cervantes, quien por otro lado lo que hizo fue retratar de manera magistral la sociedad de su época, sino llamar la atención sobre el hecho de que, hasta ahora, a casi nadie nos habían llamado la atención unas palabras que parece que no se ha sentido la necesidad de explicar, ni siquiera en su contexto, al menos en España. Y desde luego mucho menos aún discutir la pertinencia de la inclusión de esas lecturas, sin ninguna aclaración, en los programas escolares. Quizá resultan invisibles, y por eso nuestro último premio nobel, Camilo José Cela, de quien no tengo ninguna duda que habrá leído a Cervantes, acaba de afirmar hace unos días, en el Primer Congreso Internacional de la Lengua Castellana:

[L]os hispanohablantes, por fortuna para nosotros, somos el arquetipo del antirracismo puesto que nuestro denominador común es la cultura y no el color de la piel (El País, martes 8 de abril de 1997, p. 36.)

A lo mejor Cela no hace más que reflejar la dificultad de ser racista en lengua castellana, puesto que no resulta muy fácil encontrar definido el vocablo en los diccionarios españoles: exceptuando el Diccionario de la Real Academia, que recoge una versión absolutamente decimonónica ${ }^{11}$, es necesario acudir a las últimas ediciones, por ejemplo del Diccionario de Maria Moliner (Madrid: Gredos, 1988) para ver incluidos los términos "racismo" o "racista" ${ }^{12}$. En otros, como en el de Julio Casares, aún no contemplan estas voces, al menos en las ediciones que yo he consultado ${ }^{13}$.

9 Miguel DE CERvantes, La gitanilla (Leipzig: G. Freytag, 1923), p. 5.

10 He analizado ampliamente este texto de Cervantes en: "Racism as Social Exclusion: An Analysis of a Literary Representation of Gypsies by Cervantes in the 17th Spain". Ms.

11 El Diccionario de la Real Academia (Madrid: Espasa-Calpe, 1988) recoge en realidad dos acepciones, textualmente: "Exacerbación del sentido racial de un grupo étnico, especialmente cuando convive con otro u otros" y "Doctrina antropológica o política basada en este sentimiento y que en ocasiones ha motivado la persecucción de un grupo étnico considerado como inferior ${ }^{\text {. }}$.

12 En la edición de 1982 no aparece ninguno de los dos vocablos.

13 J. CASARES, Diccionario ideológico de la lengua castellana (Barcelona: Gustavo Gili, 1985). 
En la misma línea argumental, y aunque se trata de una opinión expresada con mucha menor sutileza, me gustaría citar el fragmento de un discurso que reproduce Tomás Calvo en uno de sus trabajos ${ }^{14}$ :

Yo expulsaría a los gitanos de mi pueblo y de mi país. Por supuesto que sí. Y que conste que no soy racista porque los seres de otras razas (negra, oriental, etc.) y otras religiones (judíos, protestantes, etc.) me caen todos bien. Pero hasta que los gitanos, en su mayoría, no se civilicen más, yo seguiré pensando lo mismo y no cambiaré de parecer. El día que cambien su manera de ser, no me importaría vivir con ellos en el mismo pueblo o ciudad y país ${ }^{15}$.

Se trata de un discurso poco elaborado, lo que es lógico puesto que pertenece a una persona de 18 años, de manera que, aunque al igual que Cela se niega a reconocer la presencia de racismo, éste resulta más evidente, menos invisible y menos disfrazado.

De todas formas, en realidad no se trata de negar que el racismo exista sino de afirmar que no existe aquí una reclamación que reflejó Tomás Calvo en el título de otro de sus trabajos sobre la sociedad española: Los racistas son los otros ${ }^{16}$. La definición del término racista recientemente incluida en el Diccionario de María Moliner parece coincidir con esta opinión al definirla como: "Exclusivismo de raza. En sentido restringido el practicado por el nacionalismo alemán" ${ }^{17}$.

Algunos trabajos debidos a inmigrantes en España inciden en la misma línea argumental; se podrían citar varios ejemplos al respecto, pero he elegido el siguiente fragmento del presidente de la Asociación de Trabajadores e Inmigrantes Marroquíes en España (ATIME) ${ }^{18}$ :

En conclusión, el pueblo español no es racista, pero jojo! pueden crecer grupos racistas y xenófobos si nuestra situación no mejora y estos problemas pueden afectar a toda una sociedad, [aunque matiza a continuación:] Ahora, y después del asesinato de la dominicana Lucrecia ${ }^{19}$, hay que advertir que los indicios apuntan a que esta situación va cambiando... ${ }^{20}$

14 Me refiero a T. Calvo Buezas, "La imagen de los "gitanos" en los profesores y alumnos madrileños: un estudio de la sociedad mayoritaria" En Malestar cultural y conflicto en la sociedad madrileña (Madrid: Comunidad de Madrid, 1991) pp. 305-313.

15 Op. cit., p. 312.

16 T. Calvo Buezas, Los racistas son los otros: gitanos, minorías y derechos bumanos (Madrid: Popular, 1989).

17 M. MOLINER, Diccionario de uso del español (Madrid: Gredos, 1988).

18 B. ABDEL HAMID, "Ser marroquí en España", en Hablar y dejar hablar (Sobre racismo y xenofobia), MARTín Rojo y otros, eds., (Madrid: Universidad Autónoma, 1994), pp. 263-268.

19 El asesinato de Lucrecia ha sido analizado por T. CALVO BUEZAS, El crimen racista de Aravaca (Madrid: Popular, 1993).

20 Op. cit., p. 267. 
Mi conclusión en este momento es diferente de la expresada por Abdel Hamid, y espero haber sabido argumentarla a través de los ejemplos que he elegido: En España el racismo resulta bastante invisible porque hemos aprendido a encubrirlo de manera que sólo nos atrevemos a señalarlo en los demás, o a reconocerlo en los momentos en que se hace más evidente. En la España actual ha resultado evidente ante la inmigración, y por eso se ha deducido que el racismo es un fenómeno derivado de ella. Pero los gitanos no son inmigrantes, y si el racismo es un problema derivado de la inmigración, ¿por qué entonces en el Informe Ford sobre el racismo en Europa ${ }^{21}$ que se presentó al Parlamento Europeo en 1990 se lee lo siguiente?

[E]n España el grupo étnico más amplio que sufre discriminación y a osos raciales es la población gitana nativa, [aunque añade a continuación:] entre otras comunidades que padecen actitudes de racismo y xenofobia figuran los trabajadores portugueses y marroquíes que efectúan trabajos estacionales o permanentes, pero siempre mal remunerados y considerados, y la comunidad judía ${ }^{22}$.

A una conclusión semejante llegan varios de los trabajos y de las encuestas que analizan el racismo en España, a pesar de que, como he afirmado aquí repetidas veces, lo hacen siempre en el contexto de la inmigración. Sin embargo, personalmente, me resulta una opinión paradójica, ¿o es que estamos extranjerizando a los gitanos?

\section{EL RACISMO: UNA DEFINICIÓN}

No se trata en realidad de una cuestión de extranjería, porque los estudios de racismo nunca surgieron en España relacionados con el turismo, por citar un ejemplo, sino en relación con los inmigrantes; es decir con un tipo determinado de extranjero, algo que puede quedar ilustrado con el siguiente fragmento de discurso:

Yo diferenciaría dos aspectos muy claros ¿no? lo que son las ramificaciones de las multinacionales, que en este país realmente se ha vendido todo, y yo sin ir más lejos, tengo un compañero en el trabajo que es holandés, está casado con una chica italiana y tiene unos gemelitos que están estudiando euskera, él viaja habitualmente a Holanda, donde sus suegros, a Italia, y está absolutamente inte-

${ }^{21}$ Informe Ford sobre racismo en Europa. Informe elaborado en nombre de la Comisión de Investigación del racismo y la xenofobia, sobre las conclusiones de la Comisión de Investigación (Madrid: Ministerio de Asuntos Sociales, 1991).

22 Op. cit., pp. 70-71. 
grado, Los niños son como cualquiera de nosotros y verdaderamente hay... nos vamos a tener que acostumbrar de que nuestros hijos trabajen en Burdeos, en París o vaya usted a saber dónde..., eso está clarísimo. Sin embargo, la emigración que recibimos habitualmente del sur y ahora últimamente de los países socialistas, eso plantea una situación completamente distinta; un país que no éramos lo suficientemente ricos para que nadie viniera, resulta que ahora sí somos suficientemente ricos para que vengan ino?, con todos nuestros problemas. Eso va a generar indiscutiblemente muchisimos problemas $^{23}$

Se trata de racismo, pero de racismo en otros términos, distintos de los que han sido tenidos en cuenta en nuestro país y que escapan las variables elegidas para analizar el fenómeno; es decir del número de inmigrantes y del peso simbólico de la inmigración en la sociedad mayoritaria.

Espero haber sabido emplazar al lector, a lo largo de la argumentación anterior, y sobre todo señalando las contradicciones entre lo que he llamado racismo visible y racismo invisible, en una posición adecuada para aceptar la definición de racismo que ahora propongo, y que adapto de Paul Kivel ${ }^{24}$ :

El racismo es una actitud social que legitima una distribución injusta y desequilibrada del poder, los privilegios, las tierras y los bienes materiales favoreciendo a un grupo sobre los demás ${ }^{25}$

La raza ha sido con frecuencia uno de los argumentos de legitimación utilizados, pero no el único, de la misma forma se han empleado las diferencias religiosas, el pasado histórico, etc. Actualmente se suele aludir con mayor frecuencia a las diferencias culturales. Creo que desde esta perspectiva puede entenderse por qué se exploran las actitudes racistas en relación a grupos que se distinguen actualmente según los antiguos criterios de raza, pero además también con referencia a la religión, al origen geográfico o a unas determinadas circunstancias históricas (como lo hacen las encuestas, al preguntar a los españoles sobre su opinión acerca de los «árabes, negros de África, judíos, gitanos, hispanoamericanos, filipinos, portugueses y negros norteamericanosn), sin que estas cate-

23 COLECTIVo IOE, Discurso de los españoles sobre los extranjeros (Madrid: CIS, 1995) p. 46

24 P. KIVEL, Uprooting Racism. How White People Can Work For Racial Justice (Philadelphia, PA: New Society, 1996).

25 La definición de $P$. Kivel dice textualmente: "White racism is the uneven and unfair distribution of power, privilege, land, and material goods favoring white people, Op. cit., p. 2. 
gorías resulten incongruentes entre sí en un análisis del racismo. De todas formas, el racismo no es el único camino para legitimar la desigualdad; hay otros, y tanto la historia como la variedad social extendida por el globo nos muestran ejemplos suficientes. Sin embargo es uno de los métodos más efectivos, porque su argumentanción es un tanto especial: El racismo es una argumentación circular porque consigue convertir en culpables de la desigualdad a las propias víctimas de ella; un ejemplo muy claro nos lo ofrecen los siguientes fragmentos de discursos:

Acerca de los gitanos son ellos los que no quieren integrarse en la sociedad, ni en el trabajo común. Las mujeres, por ejemplo, empiezan por vestir difef̧ente. Les das ropa, mucha ropa y buena, y no se la ponen. Ellas tienen que vestirse con sus falandranes y sus colorines ... y sus pendientes llamativos..., a lo gitano. Yo creo que lo hacen adrede, porque si vistieran bien y como las demás, no les darían limosna... No dan confianza a los payos. Porque si pueden robar, roban. Roban porque no se dedican a trabajar como los demás ... Sus trabajos son diferentes ... a lo suyo. Sus oficios de siempre... No se integran, en general, ni quieren. Lo veo muy difícil lo de los gitanos. Después en la higiene dejan mucho que desear: en el autobús, en el aula de los niños y niñas, etc. ${ }^{26}$

Me disgusta de los gitanos muchas cosas: lo vengativos y traicioneros que son; que atemorizan mucho a la gente; que no se asean para nada; que siempre están metidos en follones, juegos prohibidos, estafas, timos, etc., por lo general son unos chorizos, y la mayoría son unos analfabetos; me disgusta que físicamente muchos parecen monos debido a sus rasgos característicos, etc ${ }^{27}$

Para descubrir esta hipótesis me he basado en la crítica que, sobre un análisis sobre población categorizada como "negra" en los Estados Unidos, hace William Ryan en Blaming the Victim ${ }^{28}$ al concepto de "cultura de la pobreza" desarrollado hace ya varias décadas por Oscar Lewis.

Así pues, la propuesta de definición de racismo, incluyendo las aportaciones citadas, podría formularse de la siguiente manera:

El racismo es una actitud social que legitima una distribución injusta y desequilibrada del poder, de los privilegios, de las tierras y de los bienes materiales favoreciendo a un grupo sobre los demás, y responsabilizando de su desigual reparto a los grupos desposeídos, sobre la base de sus diferencias raciales, religiosas, étnicas o culturales, y aún más, haciendo de dichas diferencias una condición prácticamente irrenunciable e incluso hereditaria.

26 T. Calvo BuEZAS, "La imagen de los "gitanos" en los profesores y alumnos madrileños: un estudio de la sociedad mayoritaria" En: Malestar cultural y conflicto en la sociedad madrileña (Madrid: Comunidad de Madrid, 1991), pp. 311-312.

27 Op. cit., p. 312.

28 (New York: Vintage, 1971). 
Para comprender esta idea en toda su complejidad es necesario aceptar que las categorías sociales en torno a las cuales se construyen los grupos son arbitrarias ${ }^{29}$, aunque se utiliza una base explícita para conseguir un consenso social; y que en tanto que arbitrarias son, en cierta medida, manipulables. Si tomamos como ejemplo el eje simbólico blan$\mathrm{co} /$ negro en los Estados Unidos, que es uno de los casos que personalmente mejor conozco, creo que quedan bastante claros algunos de los argumentos utilizados.

Una de las bases sociales explicitas sobre las que se forma esta clasificación es el color de la piel. Sobre ella se puede obtener un cierto consenso social, porque remite a una observación simple de los rasgos físicos de las personas. Sin embargo es arbitraria por dos motivos: en primer lugar porque se podría haber elegido otra, por ejemplo el color de los ojos o el tamaño de las manos ${ }^{30}$, pero también porque entre la variedad observada de tonos de piel nos obliga a establecer un límite en un punto determinado, aquel en que un tono de pigmentación deja de llamarse "blanco" para convertirse en "negro". Y es claro que existen posibilidades de manipulación, al menos para los tonos que podríamos llamar "intermedios" 31.

29 Ver al respecto F. BARTH, Los grupos étnicos y sus fronteras. La organización social de las diferencias culturales (México: FCE, 1976).

30 Ernst Gellner denomina este tipo de clasificaciones "entrópicamente resistentes", y explica el proceso de esta forma: "... people continue to differ in all kinds of ways. People can be categorized as tall and short, as fat and thin, dark and light, and in many other ways. Clearly, there is simply no limit to the number of ways in which people can be classified. Most of the possible classification will be of no interest whatever. But some of them become socially and politically very important. They are those which I am tempted to call entropy-resistant. A classification is entropy-resistant if it is based on an attribute which has a marked tendency not to become, even with the passage of time since the initial establishment of an industrial society, evenly dispersed throughout the entire society" E. GELLNER, Nations and Nationalism (Oxford: Blackwell, 1994), p. 64.

31 Un excelente ejemplo de la "manipulación" social del concepto de negro se encuentra narrado en la novela de William FAULKNER, Light in August (Harmondsworth: Penguin, 1967), donde basta la difamación de un personaje sobre el supuesto origen negro del protagonista, para que la sociedad que le rodea empiece a considerarle como tal y justifique su desenlace fatal. Otros ejemplos excelentes se encuentran narrados en S. T. HaIzLIP, The Sweeter the Juice. Family Memoir in Black and White (New York: Simon and Shuster, 1994), donde la autora reconstruye la historia de su propia familia dividida por la ambigüedad del aspecto físico de sus miembros, que permite a algunos de ellos tomar la decisión de "pasar por blancos" y abjurar de sus parientes "negros"; y L. FUNDENBURG, Blach, White, Other. Biracial Americans Talk about Race and Identity (New York: William Morrow, 1994), que desarrolla la problemática 
Evidentemente un grupo social no se construye nunca sobre una sola base explícita, sino a partir de un entramado complicado de ellas, tratando de superponer, en la medida de lo posible, unas a otras, para que las unas ratifiquen el valor de las otras. Por ejemplo, cuando a la clasificación blanco/negro aludida en los Estados Unidos se asocia además del color de la piel, una textura determinada de pelo, un color de ojos y un tipo de ascendencia determinada.

Por último, es necesario tener en cuenta que las categorías sociales no se construyen de una forma consciente, explícita o individual, sino que son el producto colectivo de la interacción social entre una serie de individuos a lo largo de un pasado compartido, que configuran, integrando sucesivas modificaciones, el uso de unas categorías determinadas en un determinado momento.

Esta es la base sobre la que propongo el análisis del racismo en general, y el del caso español en particular, considerando las manifestaciones observadas en el mismo plano que las implícitas, como si se tratase de un iceberg del que sólo es posible apreciar a simple vista una parte mínima, aunque no por ello más real que la que queda sumergida. Pero voy a tratar de elaborar y sistematizar un poco más las hipótesis que integran este modelo de análisis.

\section{EL RACISMO: UN MODELO DE ANÁLISIS}

El principal objetivo de mi propuesta consiste en entender el racismo en el contexto de una interacción social; lo que me interesa es analizar las consecuencias sociales de las actitudes, las opiniones y los discursos racistas para los protagonistas de la relación y en la configuración de la sociedad.

Desde este punto de vista, el racismo es una actitud que interviene tanto en la configuración social como en la relación específica que pueden entablar los actores sociales, y que como tal se aprende, de forma inconsciente, al ser socializado el individuo ${ }^{32}$. Pero las sociedades no son conjuntos homogéneos coherentemente organizados, y por lo tanto algunos de sus valores entran en conflicto con otros. Esto es lo que le ocurre

de los mestizos (hijos de un progenitor blanco y otro negro) en una sociedad como la estadounidense, que no admite el concepto mismo de mestizo.

$32 \mathrm{Al}$ defender esta idea estoy argumentando en contra de que el racismo es algo "natural" en el hombre, tal y como defiende por ejemplo: D. PRACHE, Todos nacemos racistas (Zaragoza: Edelvives, 1996); por el contrario pienso que es una actitud que se aprende. 
al racismo: es una actitud que contradice abiertamente alguno de los credos compartidos por la mayoría social ${ }^{33}$ de manera que, al aprenderla se adquiere al mismo tiempo otra serie de valores en abierta contradicción con ella. El siguiente fragmento de discurso expresa claramente esta contradicción:

Pero que los nacionalismos no son buenos ¿eh?, dan origen a muchos conflictos, hay muchos problemas (...) defender lo español es una falta de solidaridad con respecto a otros pueblos por supuesto, a otras razas, a otras culturas, defender ..., eso luego tiene un aspecto positivo desde el punto de vista económico, y es que normalmente los paises con un nacionalismo fuerte suelen ser más prósperos, la gente es más trabajadora, ese orgullo por su terruño, por su patria, por su pueblo, pues le hace a veces ser más próspero y tal, el nacionalismo americano es muy típico de esas cosas ¿no? Pero lógicamente desde el punto de vista bumanitario, social,..., cristiano, etc., pues me parece super negativo ¿no? ${ }^{34}$

El resultado, o la solución hasta este momento no ha sido ni desechar el racismo, ni tampoco el credo social que se opone a él, puesto que ambos siguen siendo operativos, sino reprimir las manifestaciones más abiertas de esta actitud. Por este motivo nos encontramos ante un fenómeno, en parte observable, pero en su mayoría "invisiblen. Algo que he querido hacer gráfico utilizando la metáfora del iceberg.

Si se me acepta esta argumentación, es más fácil comprender por qué existen actitudes y actos racistas en sociedades que los sancionan negativamente; y también que para evitarlos no es sólo necesario atacar su aspecto más visible, sino la raíz, que es de alguna manera responsable, aún en franca contradicción con su declaración explícita de valores. En otras palabras, y empleando una expresión muy en boga últimamente: el racismo es "políticamente incorrecto", al menos para una mayoría; sin embargo, y por ello, también contiene un potencial demagógico y sensacionalista, porque también es una actitud social reprimida.

Ahora bien, si como he afirmado antes, el racismo está en contradicción con el credo social explícito, ¿por qué simplemente no se evita? La respuesta a esta pregunta es muy compleja, y responderla en toda su amplitud excede los límites del presente trabajo, porque exigiría un análisis mucho más profundo del que he hecho aquí, comparando los contextos en los que el racismo es visible con aquellos que he denominado

33 La contradicción entre el racismo y el credo ideológico en la sociedad norteamericana fue analizada por G. MYRDAL, An American Dilemma. The Negro Problem and Modern Democracy (New Burnswick: Transaction, 1966).

34 COlECTIVo IOE, Discurso de los españoles sobre los extranjeros. Paradojas de la alteridad (Madrid: CIS, 1995) p. 95. 
de "racismo invisible", para determinar cuándo resulta rentable, y por qué, oponerse abiertamente al credo social compartido por la mayoría, y cuándo no. Sin embargo, el modelo que propongo para entender el racismo debería al menos ofrecer alguna luz en este sentido.

Si una sociedad está constituída por un grupo de personas que comparte una serie de bienes, y además por la organización del acceso a esos bienes, tiene que arbitrar mecanismos que en la medida de lo posible sean aceptados por una mayoría, para justificar el acceso desigual a los bienes. Mi tesis es que el racismo es uno de esos mecanismos, porque es capaz de construir categorías arbitrarias sobre algunas de las diferencias observables en la variedad humana, y ordenarlas de acuerdo a una escala, que es la que justifica el acceso desigual de unos y otros grupos a los bienes sociales. Es una justificación muy efectiva porque consigue demostrar que son las propias diferencias las responsables de la desigualdad; y más aún, porque las convierte en irrenunciables e incluso en hereditarias para cada uno de los individuos que integran las distintas cate-gorías, de manera que logra hacer muy difícil (en algunos casos prácticamente imposible) el paso de un grupo a otro, un discurso muy ilustrativo a este respecto:

Yo os puedo decir que tengo a una inmigrante portuguesa dos años en mi casa que no fue para limpiarme la casa, sino fue a aprender a llevar la organización de una casa y aprender lo más básico para poder saber llevar una casa y una familia, porque vivía en un carromato hasta hace cosa de dos años ${ }^{35}$.

Se trata, por lo tanto, de un mecanismo de estratificación social muy operativo porque levanta barreras simbólicas eficaces entre unos grupos y otros, y consigue superponer criterios de clase social (en el sentido económico) sobre otros, tales como los rasgos físicos, o étnicos, o religiosos, o históricos, o culturales, que organizan jerárquicamente las categorías y su grado de derecho al acceso a los bienes.

El racismo, así entendido, es una fuerza social que permite y legitima la discriminación de arriba abajo en la escala social, de manera que a quien se discrimina es a aquellos en los que confluyen los marcadores de grupo, y que además pertenecen a los estratos socioeconómicos más bajos. Y es un argumento circular, porque hace recaer la culpa de la discriminación en las características atribuidas a los propios grupos, como si éstas fueran, por sí solas, las deficiencias que les impiden acceder a un mayor beneficio en el reparto social, y les confinan, por ello, en los estratos sociales más bajos. Me gustaría citar un ejemplo que reproduce esta idea en su discurso:

35 Colectivo IOE, op. cit., p. 40. 
Yo creo que más que una cuestión de mentalidad es una cuestión cultural; es decir, mira, se está polarizando un poco el debate entre cultura islámica y cultura cristiana, porque en realidad todo el mundo acepta perfectamente a un inglés, a un francés, a un italiano, ¿por qué?, porque a fin de cuentas es una cultura parecida, es una cultura católica, latina, inmersa en una cultura europea con unos ciertos esquemas. Entonces el choque que se está produciendo ahora es cuando entra una cultura distinta, con unos ciertos valores, pero valores radicalmente distintos a los nuestros. Es una cultura, por ejemplo la islámica; entonces ¿qué ocurre?, que la gente que viene de fuera aquí, viene con una mentalidad, (...) está llegando mucha más gente y gente ya comprometida con una cultura islámica, que ya no está buscando adaptarse a una cultura europea, podíamos decir, sino que viene con su cultura y con todo ese legajo [sic] de valores, entonces es lo que estábamos comentando también antes: choca uno cuando los valores son distintos; culturas muy bajas o clases muy bajas, pues... ${ }^{36}$.

Cuando se produce una interacción social en la que interviene este tipo de procesos, su propia complejidad impide que los actores que la protagonizan sean conscientes de lo que están haciendo. El racismo es un mecanismo para el que no se puede encontrar una finalidad inmediata o instrumental en una relación circunstancial, y creo que su sentido sólo es posible observarlo en un análisis social más profundo, del tipo que estoy proponiendo. Una justificación uinstrumental" muy típica del racismo es la que se expresa en el siguiente discurso:

...evidentemente estamos en un país con muchísimo paro y que la gente siente que la entrada de extranjeros le va a suponer a él perder un puesto de trabajo, o no conseguirlo, pues eso duele. $\mathrm{Y}$ ahí hay un racismo que no creo que sea tan elaborado como el que estamos viviendo, sino muy visceral. Yo es que eso lo he visto, por ejemplo con mis alumnos que algunos lo decían clarísimamente: "pues cómo no vamos a ser racistas, si entra aquí uno y trabaja, y me está quitando el trabajo a mín. Y claro, está muy bien todas las ideas de apertura y todo eso, pero que también hay que entender que muchas veces la gente cuando es racista tampoco lo es de forma gratuita" ${ }^{37}$.

Sin embargo, sí se pueden obtener algunas "pistas", por llamarlas de alguna manera, en determinadas interacciones. Me refiero a los prejuicios, que, como la propia palabra indica, son ideas preconcebidas formadas antes de reunir elementos suficientes para emitir un juicio. Existen mu-

36 Colectivo IOE, op. cit., p. 85.

37 Colectivo IOE, op. cit., p. 75. Sin embargo, esta relación instrumental aducida por el informante introduce una contradicción irresoluble, puesto que si el racismo es producto de la competencia se debería ser más racista respecto de aquellos que mayor competencia pueden llegar a oponer; seguramente los propios compañeros. Por este motivo reclamo que la finalidad del racismo debe buscarse fuera de la interacción social en la que se produce, que sus motivos son más complejos y más profundos. 
chos tipos de prejuicios, referidos a una variedad grande de categorías, positivos y negativos; pero los que aquí nos interesan son los que de algún modo tienen que ver con la formación de grupos sociales de manera estratificada, de manera que tenderán a ser negativos hacia abajo en la escala social y positivos hacia arriba, aunque no exclusivamente.

Los prejuicios no dependen de la experiencia directa de una persona, se aprenden de otros, se exhiben en distintos contextos buscando un consenso social y se combinan para formar los estereotipos. Los estereotipos determinan la experiencia directa, porque una vez que se han adquirido, dividen la información que se obtiene en ella, de manera que sólo se utiliza la que los refuerza, y el resto se desecha como excepción. Este proceso, que puede no ser más que una forma de simplificar y transmitir el conocimiento acumulado acerca del medio, se convierte en un mecanismo racista cuando se emplea para clasificar a las personas en grupos socialmente estratificados aparentemente en función de características físicas, religiosas, étnicas o culturales, a las cuales se asocia un comportamiento predeterminado, y por lo tanto predecible.

Por este motivo, las actitudes, las opiniones y los comportamientos racistas son independientes de la experiencia acumulada sobre esos grupos, porque sólo se emplea aquella que sirve para confirmar el estereotipo, y el resto se desecha como excepción. Esta idea explica el fracaso de todos los intentos de análisis que relacionan experiencias personales y actitudes racistas ${ }^{38}$, o su versión más simplista en el contexto español de tratar de conectar el número de imigrantes con las manifestaciones racistas.

De esta manera vuelvo al principio de mi argumentación, esperando haber sabido demostrar que el racismo en España no es una actitud derivada de la inmigración, y que es inútil tratar de encontrar variables explicativas contando inmigrantes; aunque reclamo, de la misma manera, que la inmigración nos proporciona un contexto útil para explorar el racismo si entendemos este fenómeno en toda su complejidad, porque como en toda situación de crisis social, podemos observar de forma más superficial procesos sociales internos y complejos, muy difíciles de ser acotados en una investigación.

\section{MARGARITA DEL OlMO PINTADO \\ Departamento de Estudios Árabes Instituto de Filología. CSIC}

38 Un resumen de estos intentos, así como la perpleja conclusión de que pueden utilizarse para demostrar tanto una relación directa como inversa entre estas dos variables, puede consultarse en G.E SIMPSON y J.M. YINGER, Racial and Cultural Minorities. An Analysis of Prejudice and Discrimination (New York: Plenum). 
El artículo analiza el fenómeno del racismo y trata de entender su significado sociocultural. Se ha elegido el contexto español como caso de estudio, intentando contrastar situaciones en las que el racismo es reconocido con aquellas en las que pasa desapercibido, para proponer hipótesis con las que elaborar un modelo de análisis que se ilustra con ejemplos significativos de discurso.

This paper analyzes racism in an attempt to understand what it is in social terms, and what it is for in the social arena. The Spanish context constitutes the case-study of this analysis, and the author compares recognized racist discourses with unrecognized ones. A theoretical model is proposed after some hypotheses were tested and illustrated with examples. 